Uluslararası Mühendislik

\title{
Hareketli Bir Plakadan Olan Isı Transferinin fakı Nanoakışkanlar ve Çarpan Jetle İncelenmesi
}

\section{Heat Transfer Analysis of a Moving Plate with different Nanofluids and Impining Jet}

\author{
Mustafa Kilic $^{1}$ iD, Mine Efeoğlu 1 iD \\ ${ }^{I}$ Adana Alparslan Türkeş Bilim ve Teknoloji Üniversitesi, Mühendislik Fakültesi, Makine Mühendisliği Bölümü, 01250, Adana, TÜRKiYE.
}

Başvuru/Received: 28/06/2021

Kabul / Accepted: 01/08/2021

Çevrimiçi Basım / Published Online: 31/01/2022

Son Versiyon/Final Version: 31/01/2022

\section{$\ddot{O} \mathbf{z}$}

Bu çalışmada, nanoakışkanların çarpan akışkan jet tekniği ile oluşturduğu müşterek etkinin, yüksek 1sı akılı hareketli bakır bir plakadan olan isı transferine etkisi sayısal olarak incelenmiştir. Çalışmanın ilk aşamasında, literatürdeki mevcut çalışmaları doğrulamak amacıyla temel akışkan olarak $\mathrm{Cu}-\mathrm{H}_{2} \mathrm{O}$ nanoakışkanın hareketsiz bir plakada farklı Reynolds sayılarında 1sı transfer analizi yapılmıştır. Model sonuçları literatürdeki mevcut deneysel çalışmalarla karşılaştırılmış ve doğrulanmıştır. İkinci aşamasında ise hem hareketli hem de hareketsiz bir plakada $\mathrm{Al}_{2} \mathrm{O}_{3}-\mathrm{H}_{2} \mathrm{O}$ nanoakışkanı kullanılarak farklı parçacık çaplarında, farklı plaka hızlarında, ısı transfer analizi yapılmıştır. Ayrıca hareketli bakır plakada, farklı tip nanoakışkan kullanılması durumunda 1Sı transferine olan etki de incelenmiştir. Sayısal çalışmada PHOENICS HAD programının düşük Reynolds sayılı k- $\varepsilon$ türbülans modeli kullanılmıştır. Sonuç olarak; nanoparçaçık çapı $\mathrm{D}_{\mathrm{p}}=40 \mathrm{~nm}$ 'den $10 \mathrm{~nm}$ 'ye azaltıldı̆̆ında ortalama Nusselt sayısında $\% 9,1$ 'lik artış sağlandığı tespit edilmiştir. Plaka hızı $\mathrm{V}_{\text {plaka }}=0-6 \mathrm{~m} / \mathrm{s}$ aralı̆̆ında arttırıldığında ortalama Nusselt sayısında \%88,9 oranında artış sağlandığı, farklı nanoakışkanların karşılaştırılması durumunda ise, en iyi 1sı transfer performansının $\mathrm{Cu}-\mathrm{H}_{2} \mathrm{O}$ nanoakışkanın gösterdiği belirlenmiştir.

\section{Anahtar Kelimeler}

"Çarpan akışkan jet, Hareketli plaka, HAD, Isı transferi, Nanoakışkan."

\begin{abstract}
In this study, the common effect of impinging fluid jet technique of nanofluids on heat transfer from a high heat flux moving copper plate was examined numerically. In the first phase of the study, heat transfer was analyzed for the basic fluid $\mathrm{Cu}-\mathrm{H}_{2} \mathrm{O}$ nanofluids in different Reynolds numbers on a stationary plate to confirm the current studies in the literature. The model results were compared and verified with existing experimental studies in the literature. In the second phase, heat transfer analysis was performed at different particle diameters, different plate velocities, and different volume ratios using $\mathrm{Al}_{2} \mathrm{O}_{3}-\mathrm{H}_{2} \mathrm{O}$ nanofluid on both a moving and stationary plate. Furthermore, the effect of heat transfer was examined using different types of nanofluids in the moving copper plate. In the numerical study, the low Re numbered k- $\varepsilon$ turbulence model of the PHOENICS CFD program was used. According to the study results, if the nanoparticle diameter is reduced from $D_{p}=40 \mathrm{~nm}$ to $10 \mathrm{~nm}$, the average Nusselt number increases by $9.1 \%$. When the plate velocity was raised in the range of $\mathrm{V}_{\text {plate }}=0-6 \mathrm{~m} / \mathrm{s}$, the average Nusselt number increases by $88.9 \%$. In the case of comparing different nanofluids, it is obtained that the best heat transfer performance was determined by $\mathrm{Cu}-\mathrm{H}_{2} \mathrm{O}$ nanofluid.
\end{abstract}

Key Words

"Impinging fluid jet, Moving plate, CFD, Heat transfer, Nanofluid." 


\section{Giriş}

Günümüzde teknolojinin hızla gelişmesi endüstriyel uygulamalarda kullanılan sistemlerin daha karmaşık yapıda olmasına sebep olmaktadır. Bu durum, sistemlerin ısıl yükünü arttırmakta olup sistem arızalarına sebep olmaktadır. Bu uygulamalarda sistemin verimli ve güvenli çalışabilmesi için ssıl yükün sistemden uzaklaştırılması gerekir. Bu nedenle, yüksek 1sı ve kütle transferine sahip uygulamalarda 1sı transferi oldukça önemlidir (Sun vd., 2019). Isı transferi arttırma yöntemlerinden biri olan nanoakışkanlar, temel akışkana (su, etilen glikol endüstriyel yağlar gibi) nano parçacıklar ilave edilerek oluşturulur. Nanopartikül kullanmanın önemli noktalarından biri, nanopartiküllerin, tek fazlı sıvının yoğunluk, viskozite ve termal iletkenlik gibi fiziksel özelliklerinde değişiklikler meydana getirmekte ve tek fazlı sıvınınkinden daha yüksek bir termal iletkenliğe sahip olmasıdır. Bu sebeple, nanoakışkanların gelecekte, endüstrinin birçok alanında kullanılabileceği öngörülebilir (Kakaç ve Pramuanjaroenkij, 2009).

Isı transferini arttırmak için kullanılan ve endüstride yüksek soğutma sağlayan önemli yöntemlerden birisi de çarpan jet tekniğidir. Çarpan jetler, akışkanın türbülans yoğunluğunu belirli bir bölgede yoğunlaştırarak, o bölgedeki ısıl sınır tabakayı azaltır ve yüksek 1Sı transferi sağlar. Çarpan jet tekniği tekstil ve kâğıt ürünlerinin kurutulmasında, elektronik devre elemanlarının soğutulmasında, imalatta dokunun dondurulmasında, cam levhaların temperlenmesinde, kriyocerrahide, metallerin isıl işlemlerinde, uçak endüstrisinde buzlanmayı önlemede, türbin kanatlarının soğutulmasında kullanılmaktadır. Bununla birlikte çok sayıda endüstriyel uygulama ( kâğıt ve tekstil ürünlerinin kurutulması, temperleme, metallerin 1sıl işlemi vb.) yüksek 1sı ve kütle transferine sahip hareketli plaka ile ilgilidir (Buonomo vd., 2019). Literatürdeki çalışmalar incelendiğinde nanoakışkan özelliklerinin belirlenmesine ve çarpan jetlerle ilgili akış özelliklerinin tespitine yönelik ayrı ayrı çalışmalar mevcut olmasına rağmen bu iki etkinin birlikte kullanıldığı ve ısı transferi ve akış özelliklerinin incelendiği çalışma sayısı oldukça azdır.

Literatürdeki çalışmalar incelendiğinde; nanoakışkan fikri ilk olarak Choi (1995) tarafından ortaya atılmış ve ısı transferini iyileştirdiği belirtilmiştir. Sarkar vd., (2015) ve Kasaeian vd., (2015) nanoakışkanların fiziksel ve isıl özelliklerinin belirlenmesine yönelik çalışmalar yapmışıtır. Suresh vd., (2011) ve Assef vd., (2014) tarafından nanoakışkanların ilk mühendislik uygulamaları yapılmıştır. Selvakumar ve Suresh (2012) elektronik sistemlerin soğutulması, Devdatta vd., (2009) bina 1sitma ve soğutma sistemleri, Ho vd., (2010) kaynama sürecinde nanoakışkanların ısı transferini iyileştirmesine yönelik araştırmalar yapmışlardır. Peyghambarzadeh vd., (2011) araç radyatöründe baz akışkan olarak saf su ve saf etilen glikole (EG) $\mathrm{Al}_{2} \mathrm{O}_{3}$ nanoapartikülü eklenmesi durumunda 1s1 transferine olan etkiyi deneysel olarak incelemişlerdir. Sonuç olarak, nanokışkan kullanılması durumunda, baz akışkanına kıyasla yaklaşık \% 40 'lık bir artış sağladığı ifade edilmiştir.

Lahari vd., (2018) çalışmalarında $\mathrm{TiO}_{2}-\mathrm{ZnO} / \mathrm{su}$ hibrit nanoakışkanlarınının farklı hacimsel oranlarının $(\% 0,5, \% 1,5, \% 2,0)$ 1sı transferine etkisini bir 1sı değiştiricide deneysel olarak incelemişlerdir. Sonuç olarak, $\mathrm{TiO}_{2}$ nanoakışkanının 1 sıl iletkenliği temel akışkana kıyasla \%1,5 hacimsel konsantrasyonda \%14,8' lik bir artış, hacimsel konsantrasyon \%2 olması durumunda \%27,9'luk bir artış görülmüştür. ZnO nanoakışkanın ısıl iletkenliği baz sıvısına kıyasla \%1,5 hacimsel konsantrasyonda \%11.5'luk bir artış, hacimsel konsantrasyon $\% 2$ olması durumunda \%18,1'lik bir artış görülmüsşür. Aynı hacimsel oranlarda hem 1sı transfer hızında hem de 1S1 değiştirici etkinliğinde önemli gelişme göstermiştir. Isı değiştiricisinin termal iletkenliği ve etkinliği, $\mathrm{TiO}_{2}$ ve $\mathrm{ZnO}$ hibrit nanoakışkanlarının \%1,5 hacim konsantrasyonlarında sırasıyla \% 40,9 ve \% 13,5'lik artış sağladığı tespit edilmiştir.

Xuan ve Li (2000) Cu- su nanoakışkanı için nanopartikül hacim değişiminin, partikül çapının ve partikül geometrisinin 1sı transferine olan etkisi incelenmiş̧ir. Sonuç olarak; hacimsel oran \%2,5'ten $\% 7,5$ 'e arttırılması durumunda nanoakışkan 1sıl iletkenlik katsayısı 1,24 'ten 1,78 'e arttı̆̆

Khan vd., (2021) $\mathrm{TiO}_{2} /$ su mono nanoakışkanı ile $\mathrm{TiO}_{2}-\mathrm{Ag} / \mathrm{su}$ hibrit nanoakışkanın ısıl iletkenliğini deneysel olarak karşılaştırmışlardır. Çalışmada incelenen parametreler; farklı hacimsel konsantrasyonlar $(0,1,0,2,0,3,0,4)$ ve farklı akışkan sıcaklıkları $\left(35^{\circ} \mathrm{C}, 40^{\circ} \mathrm{C}, 50^{\circ} \mathrm{C}\right.$, $\left.60^{\circ} \mathrm{C}\right)$ dır. Sonuç olarak hem mono hem de hibrit nanoakışkanın, nanoakışkan sıcaklığı ve nanopartikül hacimsel konsantrasyonu artmasıyla termal iletkenliği arttığı ancak nanokompozit akışkanın ısıl iletkenlik artışının, mono nanoakışkandan daha yüksek olduğu belirlenmiştir. $\mathrm{TiO}_{2} / \mathrm{su}$ nanoakışanı için $\% 4$ hacimsel konsantrasyonda ve $60^{\circ} \mathrm{C}^{\prime}$ de $\% 18,4^{\prime}$ lik maksimum iyileşme sağlanmıştır. Nanokompozit akışkanın $40^{\circ} \mathrm{C}$ 'deki 1 sıl iletkenliği, $60^{\circ} \mathrm{C}$ 'deki mono nanoakışkanın iletkenliğiyle aynı değere sahip olduğu tespit edilmiştir.

Çarpan akışkan jetlerle ilgili çalışmalar incelendiğinde; Sharif ve Banerjee (2008) 1sıtılmış hareketli bir plakaya çarpan jetin 1sı transferine etkisini sayısal olarak incelemişlerdir. Jet çıkış Reynolds sayısı $(R e=5000-20000)$, farklı plaka hızları $\left(U_{\text {plaka }}=0-2 \mathrm{~m} / \mathrm{s}\right)$ ve jet-çarpma plakası mesafesi $(\mathrm{H} / \mathrm{W}=6-8)$ çalışmada incelenen parametrelerdir. Sayısal analiz için standart $\mathrm{k}-\varepsilon$ türbülans modeli kullanılmıştır. Sonuç olarak, plakada hareket olmadığında jet plakaya çarptı̆̆ında jetin her iki tarafında iki ters yönde dönen birincil girdapların oluştuğu, ancak plaka hareket ettiğinde akış çizgileri sağa doğru eğildiği belirlenmiştir. Jet Reynolds sayısı ve plaka hızının artması ortalama Nusselt sayısında önemli bir artış sağladığı tespit edilmiştir. Kilic vd., (2017) sabit 1sı akılı düz bir plakanın çarpan akışkan hava jeti yardımı ile soğutulmasını farklı parametreler için incelemiştir. $\mathrm{Re}=4000-10000$ aralığında arttırılması ortalama Nusselt sayısında $\% 49,5^{\prime}$ lik bir artış sağlandığı, $\mathrm{H} / \mathrm{D}_{\mathrm{h}}=4-10$ aralığında arttırılmasında ise \% 17,9'luk artış sağlandığ belirlenmiştir. Kilic ve Başkaya (2017) soğutucu olarak çarpan akışkan jet kullanılan sabit 1sı akılı bir yüzeyde 1sı transferinin farklı geometride akış yönlendiriciler kullanılarak iyileştirilmesini sayısal olarak incelemişlerdir. Sonuç olarak; 1sı transferinde akış yönlendirici kullanılmasının, akış yönlendirici kullanılmaması durumuna göre \%28'e oranında bir artış sağlayabildiği görülmüştür. 
Nanoakışkan ve çarpan jetlerin müşterek etkisini inceleyen çalışmalar incelendiğinde; Buonomo vd., (2019) nanoakışkanın 1sıttılmış hareketli bir yüzeye çarptırılmasıyla oluşan ortak etkinin akış ve ısı transfer analizini sayısal olarak incelemişlerdir. Çalışma sıvısı olarak su ve $\mathrm{Al}_{2} \mathrm{O}_{3}$-su nanoakışkanı kullanılmıştır. Sayısal model için ANYSYS FLUENT paket programının k- $\varepsilon$ türbülans modeli kullanılmıştır. Çalışmada, jet-hedef yüzey mesafesinin (H/W=6-10) iki değeri için iki geometrik yapı oluşturulmuştur. Nanopartikül konsantrasyonu $\varphi=0 \%-6 \%$ aralığında, Reynolds sayısı $R e=5000,20000$ değerlerinde, plaka hızı $U_{p}=0 \mathrm{~m} / \mathrm{s}, 0,8 \mathrm{~m} / \mathrm{s}, 2 \mathrm{~m} / \mathrm{s}$ aralığında çalışılmıştır. Sonuç olarak; haraketli plaka çarpma noktasında yerel Nusselt sayısını önemli ölçüde azaltmıştır. Reynolds değeri ve plaka hızı arttıkça ortalama Nusselt sayısı artmıştır. Hacimsel oran ve jet-hedef yüzey mesafe oranı arttıkça yerel Nusselt sayısı da artmıştır. Nanoakışkanın kullanılması durumunda viskozitede artış meydana gelmiştir bu da hareketli plakanın daha fazla sürüklenmesine ve hareketli yüzeyden daha fazla kütle akış oranının olduğu belirlenmiştir.

Barewar vd., (2019) ZnO-su nanoakışkanının ısıtılmış bakır levha yüzeyine çarptırılması ile ısı transfer özelliklerini farklı jet-plaka yüzey mesafesi $(2-7,5)$ ve farklı hacim konsantrasyonunda $(\phi=\% \quad 0,02-\% 0,1)$ deneysel olarak incelemişlerdir. Sonuç olarak; $\mathrm{ZnO}$ nanoakışkanı için partikül konsantrasyonu arttıkça 1sı transferinde artış meydana geldiği, hacimsel konsantrasyon $\phi=\% 0.1$ olması durumunda saf su ile karşılaştıııldığında 1sı transferinde \%51'lik bir artış görülmüştür. Jet-plaka (H/D) mesafesinin jet çarpma soğutma işleminde önemli olduğu ve $\mathrm{ZnO}$ nanoakışkanı $\phi=\%$ 0,1 hacimsel konsantrasyonda jet-plaka mesafesi $\mathrm{H} / \mathrm{D}=3,5$ olması durumunda 1s1 transferinde maksimum iyileşme olduğu tespit edilmiştir. Kilic ve Ali (2019) çalışmalarında nanoakışkanlar ve çoklu jetler kullanılması durumunda 1Sı transferi ve akış özelliklerini incelemişlerdir. Sonuç olarak; nanoakışkan hacim oranının $\phi=\% 2-\% 4$ aralığında arttırıldığında ortalama Nusselt sayısının \%10,4 arttığı, en iyi 1sı transferi performansının Cu-su nanoakışkanı ile elde edildiği ve çoklu jetlerin konumlarının 1sı transferinde önemli bir belirleyici olduğunu tespit etmişlerdir. Ersayın ve Selimefendigil (2013) hareketli bir plakaya $\mathrm{Al}_{2} \mathrm{O}_{3}$-su nanoakışkanı için oluşturulan çarpan jetin, titreşimli ve titreşimli olmayan akışın ısı transferi ve akış özellikleri sayısal olarak incelenmiştir. Sayısal çalışmada nanopartikül hacim oranı $(\varphi=0,2,4,6)$, plaka hızı $\left(\mathrm{U}_{\text {plaka }}=0,25,0,5,1,2\right)$ Reynolds sayısı $(\mathrm{Re}=100,200,400)$, nanopartikül titreşim frekansı $(1 \mathrm{~Hz}, 2 \mathrm{~Hz}, 4 \mathrm{~Hz}, 8 \mathrm{~Hz})$ değerlerinde çalışılmıştır. Plaka hızı değişirken nanopartikül hacimsel konsantrasyonu $\phi=\% 4$ ve Reynolds değeri Re=100 alınmıştır. Sonuç olarak; plaka hareketsiz durumdayken çarpan jet plakanın sağ ve sol bölümlerinde simetrik iki girdap oluşturduğu ancak plaka + x yönünde hareket ettiğinde termal ve hız akım çizgilerinin sağa doğru eğildiği tespit edilmiştir. Düşük plaka hızlarında, jet akışının durma noktaları daha belirgin olduğu ve bu noktalarda Nusselt sayısının maksimum değere ulaştığı ancak artan plaka hızları için bu belirginliğin azaldığı tespit edilmiştir. Nanopartikül hacimsel konsantrasyonu arttıkça toplam ısı transfer oranın arttığı belirlenmiştir. Titreşimli jet çarpması için frekansın artması toplam 1Sı aktarım hızını arttırdığı tespit edilmiştir.

Başaran ve Selimefendigil (2013) laminer bir akış için 1sıtılmış, hareketli bir plakaya çift çarpan jetlerin dikdörtgen bir kanalda 1sı transferini sayısal olarak incelemişlerdir. Çalışma sıvısı olarak su ve $\mathrm{Al}_{2} \mathrm{O}_{3}$-su nanoakışkanı kullanılmıştır. Jet çıkış Reynolds sayısı $(\operatorname{Re}=50-200)$, plaka hızı $\left(\mathrm{U}_{\mathrm{p}}=0,0.5,1,2 \mathrm{~m} / \mathrm{s}\right)$ ve nanoakışkan hacimsel oran $(\varphi=0 \%-6 \%)$ etkisi araştırılmıştır. Sayısal analiz için FLUENT paket programı kullanılmıştır. Sonuç olarak, plaka hızı arttıkça Nusselt sayısı artmıştır. Nusselt sayısındaki maksimum artış sabit plakada çarpma bölgesinin yakınında, hareketli plakada ise çıkışta elde edilmiştir. Re sayısı arttıkça, 1sıl sınır tabaka incelmiş ve böylece 1sı transferi artmıştır. Nanopartikül hacimsel oranın artması Nusselt sayısını arttırdığı tespit edilmiştir.

$\mathrm{Bu}$ çalışmada, farklı tipte nanoakışkanların, 1sı transferini arttırma yöntemlerinden biri olan çarpan akışkan jet tekniği ile kullanılmasıyla, hareketli bir yüzeyden olan 1Sı transferi arttırılmaya çalışılmışıtır. Literatürde yer alan çalışmalardan farklı olarak nanoakışkanlar, çarpan jet tekniği ile kullanılmış ve bu durumda oluşan müşterek etkinin 1sı transferine etkisi, farklı parametreler için incelenmiş ve deneysel sonuçlarla doğrulanmıştır. Bu çalışmadaki temel amaç; son derece karmaşık olan nanoparçacıkların temel akışkan içindeki davranışlarının belirlenmesi, nanoakışkanların çarpan jet tekniğinde kullanılması ile oluşan yoğun türbülans etkilerinin ortaya konması ve bunun 1sı transferine olan etkisinin modellenmesi ve bu modelin literatürde yer alan deneysel sonuçlarla doğrulanmasıdır.

\section{Materyal ve Metot}

\subsection{Model Geometrisi}

$\mathrm{Bu}$ çalışmada, nanoakışkanlar kullanılarak hareketli bir plakadan olan 1sı transferinin iyileştirilmesi sayısal olarak incelenmiştir. Problem zamandan bağımsız olarak çözülmüştür. Çalışmada, hedef plaka boyutları 110x40x32 cm olarak modellenmiş̧ir. Kanal boyunca yerleştirilmiş plakanın yüzeyinde sabit $1 \mathrm{~s} 1$ akısı $\left(q "=222000 \mathrm{~W} / \mathrm{m}^{2}\right)$ olduğu kabul edilmiştir. Sayısal analiz için farklı türbülans modelleri denenmiş ve uygulanan Reynolds değerinde deney sonuçları ile uyumlu sonuçlar elde edildiğinden, PHOENICS HAD programının düşük Re sayılı k-e türbulans modeli kullanılmıştır. Kütlenin korunumu, momentum ve enerji denklemlerine uygun sınır şartları verilerek oluşturulan modelde ışınımla olan isı transferi ihmal edilmiş ve sadece türbülanslı, zorlanmış taşınımla olan isı transferi dikkate alınmıştır. Şekil 1'de problemin HAD model geometrisi ve Şekil 2'de hücre yapısı gösterilmiştir. 


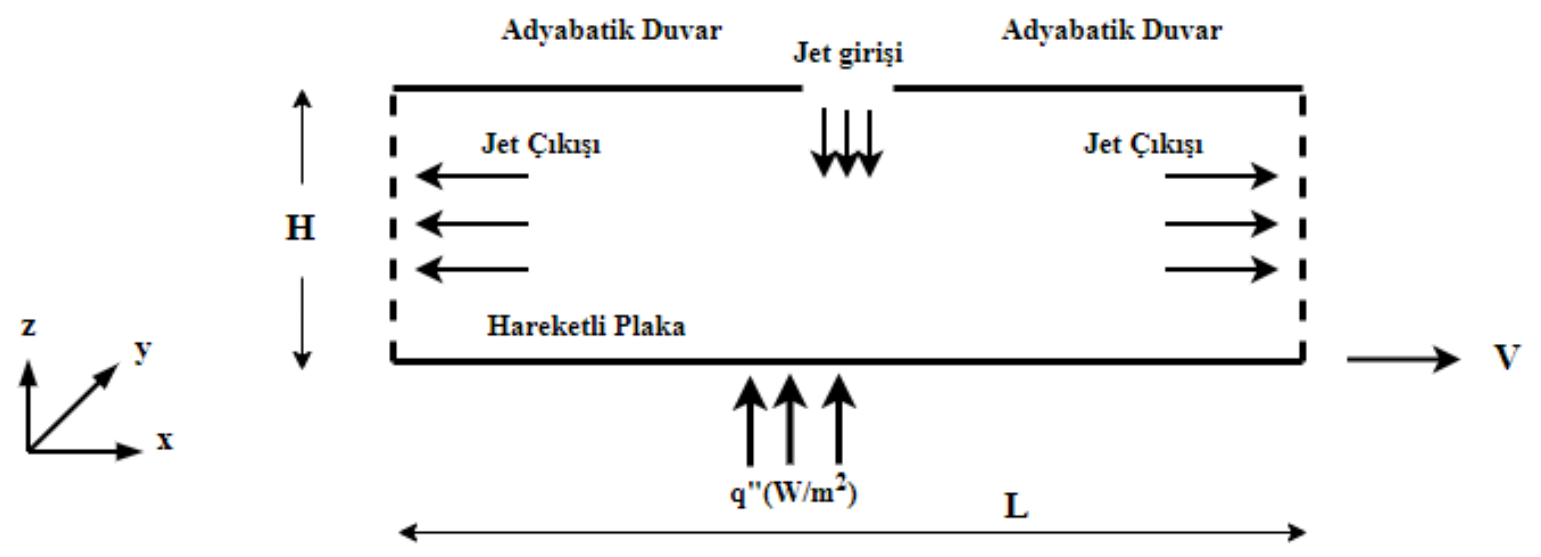

Şekil 1. HAD model geometrisi

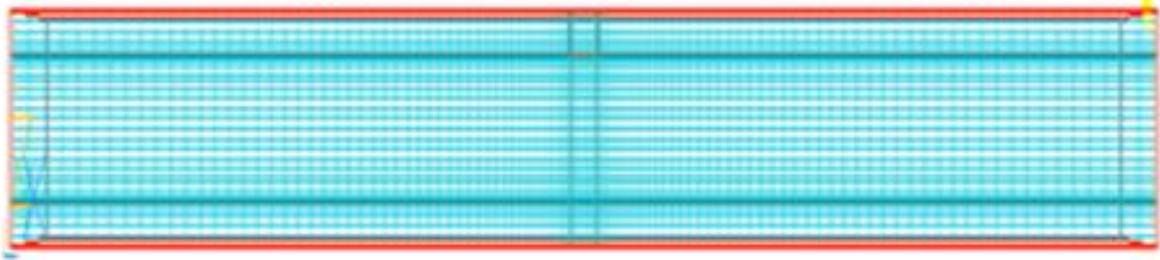

Şekil 2. Hücre yapıs1

Korunum denklemleri:

$\frac{\partial U_{i}}{\partial x_{i}}=0$

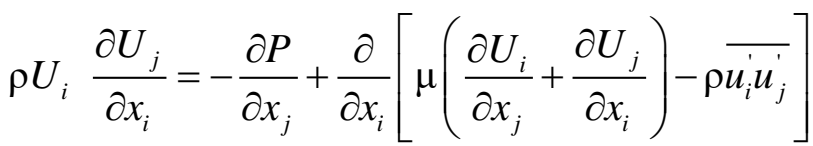

$\rho c_{p} U_{i} \frac{\partial T}{\partial x_{i}}=\frac{\partial}{\partial x_{i}}\left[k \frac{\partial T}{\partial x_{i}}-\rho c_{p} \overline{u_{i}^{\prime} T^{\prime}}\right]$

Modelin taşıma denklemleri:

$\rho U_{i} \frac{\partial k}{\partial x_{i}}=\frac{\partial}{\partial x_{i}}\left[\left(\mu+\frac{\mu_{t}}{\sigma_{k}}\right) \frac{\partial k}{\partial x_{i}}\right]+\mu_{t}\left(\frac{\partial U_{i}}{\partial x_{j}}+\frac{\partial U_{j}}{\partial x_{i}}\right) \frac{\partial U_{i}}{\partial x j}-\rho \varepsilon$

$\rho U_{i} \frac{\partial \varepsilon}{\partial x_{i}}=\frac{\partial}{\partial x_{i}}\left[\left(\mu+\frac{\mu_{t}}{\sigma_{\varepsilon}}\right) \frac{\partial \varepsilon}{\partial x_{i}}\right]+f_{1} C_{1} \mu_{t} \frac{\varepsilon}{k}\left(\frac{\partial U_{i}}{\partial x_{j}}+\frac{\partial U_{j}}{\partial x_{i}}\right) \frac{\partial U_{i}}{\partial x_{j}}-f_{2} C_{2} \rho \frac{\varepsilon^{2}}{k}$

Türbülanslı kinetik viskozite:

$\mu_{t}=f_{\mu} C_{\mu} \rho \frac{k^{2}}{\varepsilon}$ 
$\sigma_{k}=1.00 ; \quad \sigma_{\varepsilon}=1.314 ; \quad C_{1}=1.44 ; \quad C_{2}=1.92 ; \quad C_{\mu}=0.09$

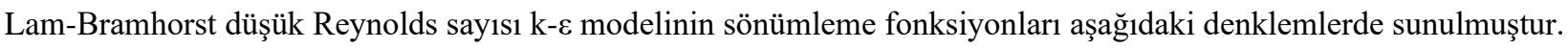

$f_{\mu}=\left[1-\exp \left(-0.0165 R e_{z}\right)\right]^{2}\left(1+\frac{20.5}{R e_{t}}\right)$

$f_{1}=\left(1+\frac{0.05}{f_{\mu}}\right)^{3}$

$f_{2}=1-\exp \left(-\mathrm{Re}_{t}^{2}\right)$

Burada,

$\operatorname{Re}_{t}=\frac{\rho k^{2}}{\mu \varepsilon}$

$\operatorname{Re}_{z}=\frac{\rho k^{1 / 2} z}{\mu}$

Bu çalışmada kullanılan sınır şartları Tablo 1'de gösterilmiş̧ir. Bu çalışmada; kanal çıkışında x yönündeki U,V,W hızları ile türbülans kinetik enerjisi ve yayılma oranının değişmediği, kanal çıkışından kanal içerisine bir ters akışın olmadığı ve deney düzeneğinde kanal uzunluğunun daha uzun olduğu ve çıkışın daha ileriki bir bölgeden meydana geldiği kabulü yapılmıştır.

Tablo 1. Sınır şartları.

\begin{tabular}{lcccccc} 
& $\mathbf{U}(\mathbf{m} / \mathbf{s})$ & $\mathbf{V}(\mathbf{m} / \mathbf{s})$ & $\mathbf{W}(\mathbf{m} / \mathbf{s})$ & $\mathbf{T}(\mathbf{K})$ & $\mathbf{k}$ & $\varepsilon$ \\
\hline Jet & $\mathrm{U}=0$ & $\mathrm{~V}=0$ & $\mathrm{~W}=\mathrm{W}_{\text {giris }}$ & $\mathrm{T}=\mathrm{T}_{\text {giris }}$ & $\left(T_{\mathrm{i}} W_{\text {jet }}\right)^{2}$ & $\left(C_{\mu} C_{d}\right)^{3 / 4} \frac{k^{3 / 2}}{L}$ \\
Plaka & $\mathrm{U}=\mathrm{U}_{\text {plaka }}$ & $\mathrm{V}=0$ & $\mathrm{~W}=0$ & $\mathrm{q}^{\text {" }=\text { "q"yüzey }}$ & $k=0$ & $\frac{\partial \varepsilon}{\partial z}=0$ \\
Çıkış & $\frac{\partial U}{\partial x}=0$ & $\frac{\partial V}{\partial x}=0$ & $\frac{\partial W}{\partial x}=0$ & $\mathrm{~T}=\mathrm{T}_{\text {çikıs }}$ & $\frac{\partial k}{\partial x}=0$ & $\frac{\partial \varepsilon}{\partial x}=0$ \\
$\begin{array}{l}\text { Ön ve } \\
\text { Arka } \\
\text { Duvar }\end{array}$ & $\mathrm{U}=0$ & $\mathrm{~V}=0$ & $\mathrm{~W}=0$ & $\frac{\partial T}{\partial y}=0$ & -- & -- \\
$\begin{array}{l}\text { Üst } \\
\text { Duvar }\end{array}$ & $\mathrm{U}=0$ & $\mathrm{~V}=0$ & $\mathrm{~W}=0$ & $\frac{\partial T}{\partial z}=0$ & -- & -- \\
\hline
\end{tabular}

\subsection{Matematiksel Formülasyon}

$\mathrm{Bu}$ çalışmada iletimle ve ışınımla olan 1sı kayıpları ihmal edilmiş ve yüzeyde tanımlanan isı akısının tamamının taşınımla akışkana geçtiği kabulü yapılmıştır.

Yüzeyden taşınımla olan 1sı transferi;

$Q_{\text {taşınım }}=h \cdot A \cdot \Delta T$ 
Burada $\mathrm{Q}_{\text {tasıım }}$ hedef plaka yüzeyindeki 1sı değeri, $h$ ssı taşınım katsayısı, $A$ taşınım yüzey alanı, $\Delta T\left(\Delta T=T_{\text {yüzey }}-T_{\text {yğ̆n }}\right)$ ölçülen yüzey sıcaklığı ile akışkan ortalama sıcaklığı arasındaki farktır.

Nusselt sayıs1 $(\mathrm{Nu})$;

$$
N u=\frac{\left(Q_{t a s i n ı m} \cdot D_{h}\right)}{\left(T_{y \ddot{z} z e y-T} T_{y \iota ̆ ̆}\right) \cdot k_{n f}}
$$

Burada $T_{s}$ ölçülen yüzey sıcaklığı, $D_{h}$ hidrolik çap ve $k_{n f}$ ise nanoakışkan ısı iletkenlik katsayısıdır.

Ortalama Nusselt sayısı ise;

$N u_{\text {ort }}=\frac{h_{\text {ort }} \cdot D_{h}}{k_{n f}}$

Reynolds sayısı $(R e)$; akış karakteristiğinin belirlenmesinde (akışın laminer veya türbülanslı olup olmadığını belirlemek için) kullanılmaktadır. Reynolds sayısı;

$\operatorname{Re}=\frac{\left(\rho_{n f} \cdot V_{j e t} \cdot D_{h}\right)}{\left(\mu_{n f}\right)}$

Burada $\rho_{n f}$ nanoakışkan yoğunluğu, $V_{j e t}$ jet çıkış hızı ve $\mu_{n f}$ nanoakışkan dinamik vizkozitesidir.

Nanoakışkan yoğunluğu ise (Pak ve Cho 1998) eşitliği ile hesaplanmıştır;

$$
\rho_{n f}=(1-\varphi) \cdot \rho_{b f}+\varphi \cdot \rho_{p}
$$

Burada $\rho_{b f}$ temel akışkan (su) yoğunluğu, $\varphi$ nanoakışkan hacimsel oranı, $\rho_{p}$ ise nanoakışkan içerisindeki katı parçacıkların yoğunluğudur.

Nanoakışkan hacimsel oranı ise;

$$
\varphi=\frac{1}{(1 / \omega) \cdot\left(\rho_{p}-\rho_{b f}\right)}
$$

Burada $\omega$ nanoakışkan ile temel akışkanın yoğunlukları arasındaki farktır (Pak ve Cho 1998).

Nanoakışkan özgül ısısı ise (Wang vd., 2006);

$$
C_{p_{n f}}=\frac{\varphi \cdot\left(\rho \cdot C_{p}\right)_{p}+(1-\varphi) \cdot\left(\rho \cdot C_{p}\right)_{f}}{\left(\rho_{n f}\right)}
$$

Burada $\rho_{n f}$ nanoakışkanın yoğunluğu, $C_{p(p)}$ parçacığın özgül 1sısı, $C_{p(f)}$ temel akışkanın özgül ısısıdır.

Nanoakışkanın ısı iletim katsayısı ise (Corcione, 2011);

$\frac{k_{n f}}{k_{b f}}=1+4,4 \operatorname{Re}^{0,4} \operatorname{Pr}_{b f}^{0,66}\left[\frac{T}{T_{f r}}\right]^{10}\left[\frac{k_{p}}{k_{b f}}\right]^{0,03} \varphi^{0,66}$

Burada $\operatorname{Re}_{\mathrm{p}}$ nanoparçacık Reynolds sayısı $\left(R e_{p}=\frac{2 \rho_{b f k_{b f} T}}{\pi \mu_{b f}^{2} d_{p}}\right), \varphi$ parçacık hacimsel oranı, Pr $\mathrm{bf}_{\mathrm{bf}}$ temel akışkan Prandtl sayısı, T nanoparçacık sıcaklığı, $\mathrm{T}_{\mathrm{fr}}$ temel akışkan donma sıcaklığı, $k_{b f}$ temel akışkanın iletim katsayısı, $\mathrm{k}_{\mathrm{p}}$ ise nanoparçacıkların $1 \mathrm{~s} 1$ iletim katsayısidır.

Nanoakışkanın dinamik vizkozitesi ise şu şekilde hesaplanmıştır (Batchelor, 1977).

$\mu_{\mathrm{nf}}=\mu_{\mathrm{bf}}\left(1+2,5 \varphi+4,698 \varphi^{2}\right)$

Burada $\varphi$ nanoakışkan hacimsel oranı, $\mu_{\mathrm{bf}}$ ise temel akışkanın dinamik vizkozitesidir.

\subsection{Sayısal Sonuçların Doğrulanması}

Bu çalışmada; yüzeylere yakın bölgelerde hidrodinamik sınır tabakada meydana gelebilecek değişimlerin daha iyi modellenebilmesi maksadıyla hücre yapısı jet girişi ve bakır plakanın yüzeyinde yoğunlaştırılmıştır. Öncelikle sayısal sonuçların iterasyon sayısından ve 
hücre sayısından bağımsızlaştırılması sağlanmıştır. Buna göre; iterasyon sayısı 1000 ile 5000 arasında, hücre sayısı 25 ve 34 aralığında (z yönünde) çalışılmıştır. Sonuç olarak; hücre sayısı 110x40x32 ve iterasyon sayısı 3000 olduğunda sonuçların hücre sayısından ve iterasyon sayısından bağımsız olduğu görülmüsşür. Çalışmada Reynolds değerleri Re=16000 olarak alınmıştır. Bu sebeple, düşük Re sayılı k- $\varepsilon$ türbülans modeli kullanılmıştır. Elde edilen sayısal sonuçlar, deneysel sonuçlar (Li vd., 2012) ile karşılaştırılmış ve arasındaki

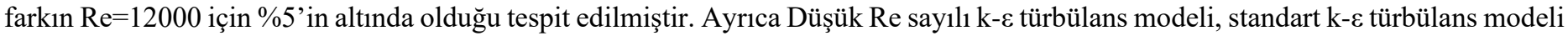
ve standart k- $\omega$ türbülans modeli ile karşılaştırılmış ve deney sonuçlarını daha iyi bir şekilde temsil edebildiği görülmüştür. Farklı türbülans modelleri kullanılarak elde edilen sayısal sonuçların deney sonuçlar ile karşılaştırılması Şekil 3’te sunulmuştur.

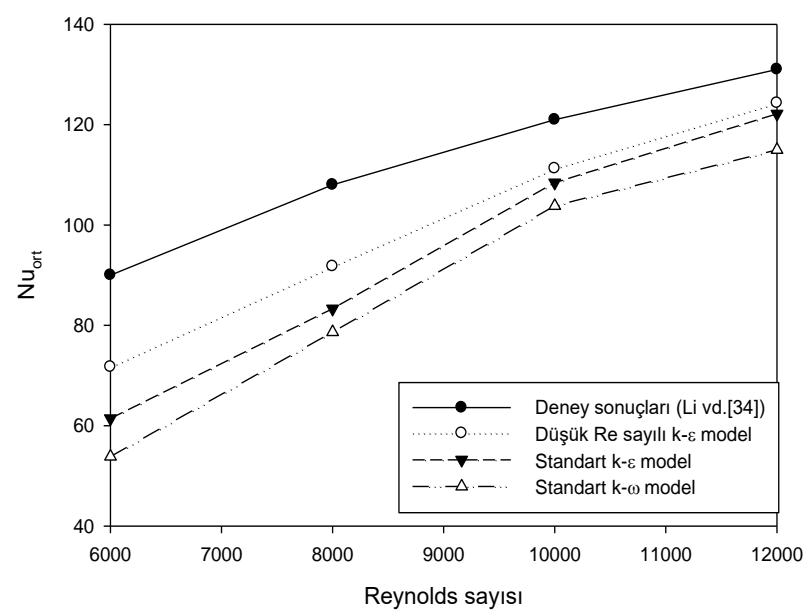

Şekil 3. $\mathrm{Cu}-\mathrm{H}_{2} \mathrm{O}$ nanoakışkanı için model sonuçlarının deney sonuçları ile $(\varphi=\% 1,5)$ karşılaştırılması (Li vd., 2012).

\section{Bulgular ve Tartışma}

Bu bölümde sayısal sonuçlar 3 farklı parametre için incelenmiştir. Çalışmada incelenen parametrelerin sonuçları aşağıda sunulmuş̧tur.

\section{1 $\mathrm{Al}_{2} \mathrm{O}_{3}-\mathrm{H}_{2} \mathrm{O}$ Nanoakışkanın Farkı Parçacık Çaplarında Isı Transferine Etkisi ( $\left.\mathrm{V}_{\text {plaka }}=\mathbf{2} \mathrm{m} / \mathrm{s}\right)$}

$\mathrm{Bu}$ parametrede $\mathrm{Al}_{2} \mathrm{O}_{3}-\mathrm{H}_{2} \mathrm{O}$ nanoakışkanı kullanılarak oluşturulan bir çarpan jet için, farklı parçacık çaplarının $\left(D_{\mathrm{p}}=10 \mathrm{~nm}, 20 \mathrm{~nm}\right.$, $30 \mathrm{~nm}, 40 \mathrm{~nm}$ ) $1 \mathrm{~s} 1$ transferine etkisi incelenmiştir. Jet giriş sıcaklığ $1 T_{\text {giriş }}=20^{\circ} \mathrm{C}, \mathrm{Re}=16000$ ve plaka hızı $\mathrm{V}_{\text {plaka }}=2 \mathrm{~m} / \mathrm{s}$ 'dır. Şekil $4^{\prime}$ te yerel Nusselt sayısını, farklı nanoparçacık çapları için değişimi gösterilmiştir. Şekil 5’te ise ortalama Nusselt sayısının değişimi sunulmuştur.

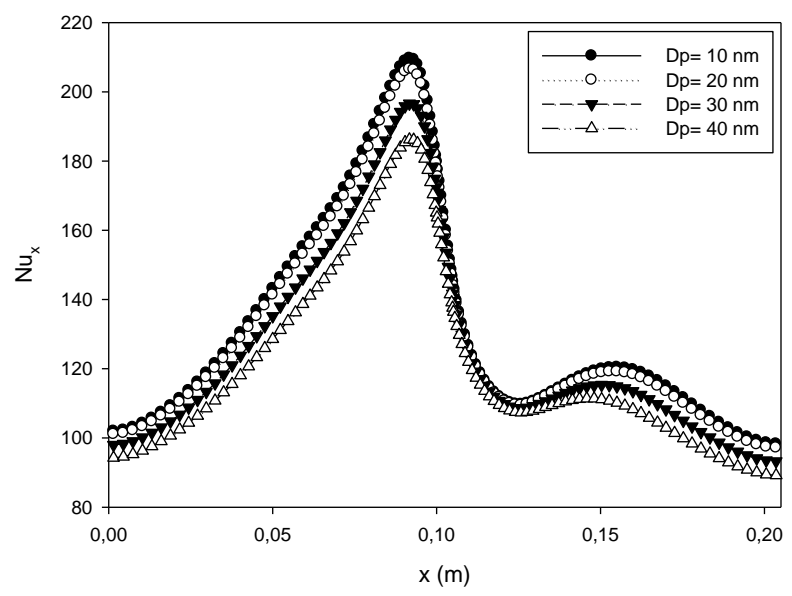

Şekil 4. Farklı parçacık çaplarının yerel Nusselt sayısına etkisi. 


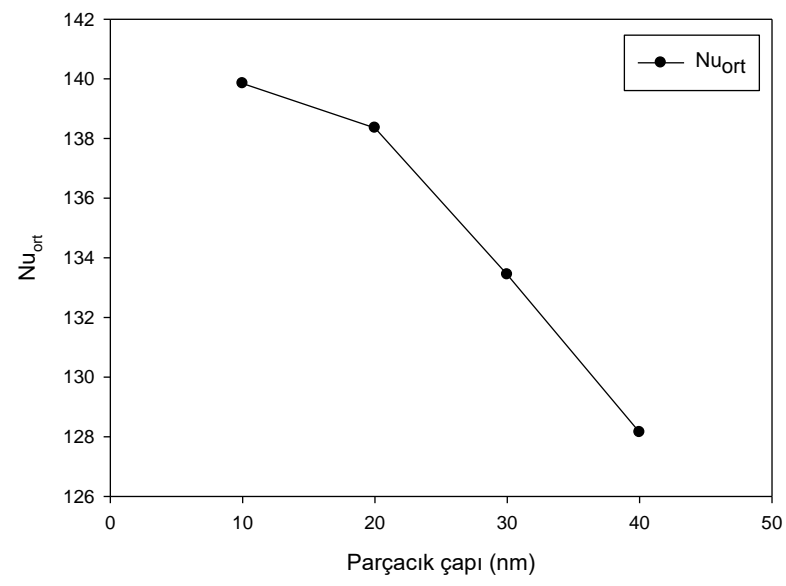

Şekil 5. Farklı parçacık çaplarının ortalama Nusselt sayısına etkisi.

Nanoakışkan parçacık çapı azaldıkça (katı parçacık yüzey alanının arışına bağlı olarak) ortalama Nusselt sayısının arttığı ve yüzey sıcaklığının düştüğü belirlenmiştir. Ancak ortalama Nusselt sayısındaki bu artışın, azalan parçacık çapları için azalarak devam ettiği tespit edilmiştir. Parçacık çapı $\mathrm{D}_{\mathrm{p}}=40-30 \mathrm{~nm}$ aralığında azaltıldığında ortalama Nusselt sayısında \% 4,1'lik bir artı̧̧ olduğu, $\mathrm{D}_{\mathrm{p}}=30-20$ $\mathrm{nm}$ aralığında azaltıldığında \% 3,7'lik bir artış olduğu, $\mathrm{D}_{\mathrm{p}}=20-10 \mathrm{~nm}$ aralığında azaltıldığında ise 1 sı transferinde \% $1,1^{\prime}$ lik bir artış olduğu belirlenmiştir. En yüksek ısı transfer artışının, $D_{p}=40-10 \mathrm{~nm}$ aralığında azaltıldığında, ortalama Nusselt sayısında \% 9,1 olarak meydana geldiği belirlenmiştir. Şekil 6'da plaka yüzeyinde oluşan sıcaklık konturları $D_{p}=10 \mathrm{~nm}$ ve $D_{p}=40 \mathrm{~nm}$ değerleri için gösterilmiştir.

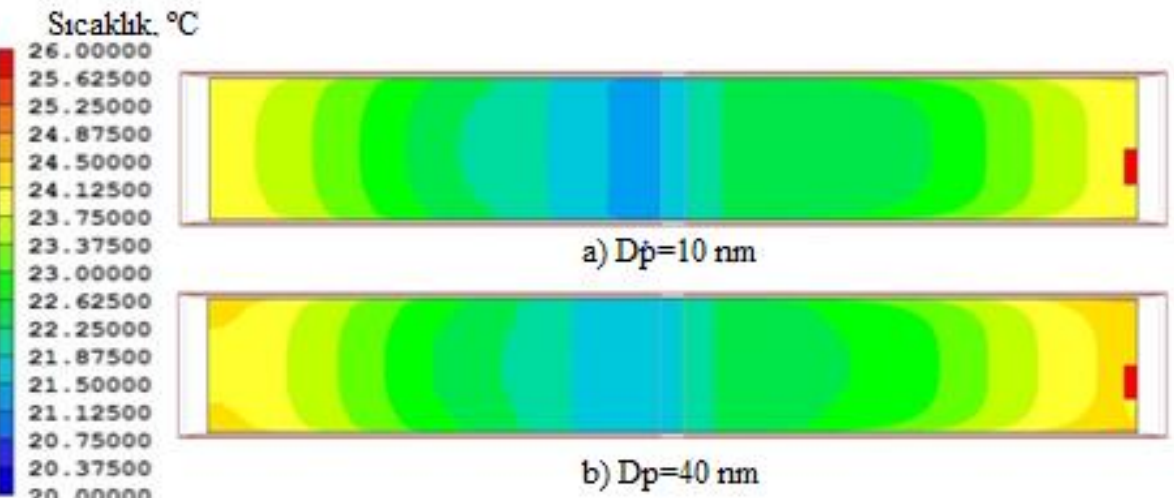

Şekil 6. Plaka Sicaklık konturları (a) $D_{p}=10 \mathrm{~nm}$ (b) $D_{p}=40 \mathrm{~nm}$

\section{2 $\mathrm{Al}_{2} \mathrm{O}_{3}-\mathrm{H}_{2} \mathrm{O}$ Nanakışkanının Farklı Plaka Hızlarında Isı Tranferine Etkisi ( $\left.\mathrm{V}_{\text {plaka }}=0 \mathrm{~m} / \mathrm{s}, \mathbf{2 m} / \mathrm{s}, \mathbf{4 m} / \mathrm{s}, 6 \mathrm{~m} / \mathrm{s}\right)$}

$\mathrm{Bu}$ parametrede $\mathrm{Al}_{2} \mathrm{O}_{3}-\mathrm{H}_{2} \mathrm{O}$ nanoakışkanı kullanılarak oluşturulan bir çarpan jet için, farklı plaka hızlarının $\left(\mathrm{V}_{\text {plaka }}=0 \mathrm{~m} / \mathrm{s}, 2 \mathrm{~m} / \mathrm{s}, 4 \mathrm{~m} / \mathrm{s}\right.$, $6 \mathrm{~m} / \mathrm{s})$ 1sı transferine etkisi incelenmiştir. Nanoakışkanlar $\phi=2,0$ hacimsel orandadır. Jet giriş sıcaklığ $\mathrm{T}_{\text {giriş }}=20^{\circ} \mathrm{C}$, ve Reynolds sayıs $\mathrm{Re}=16000$ 'dir. Şekil 7'de farklı plaka hızları için elde edilen yerel Nusselt sayısının değişimi, Şekil 8'de ortalama Nusselt sayısının değişimi verilmiştir. 


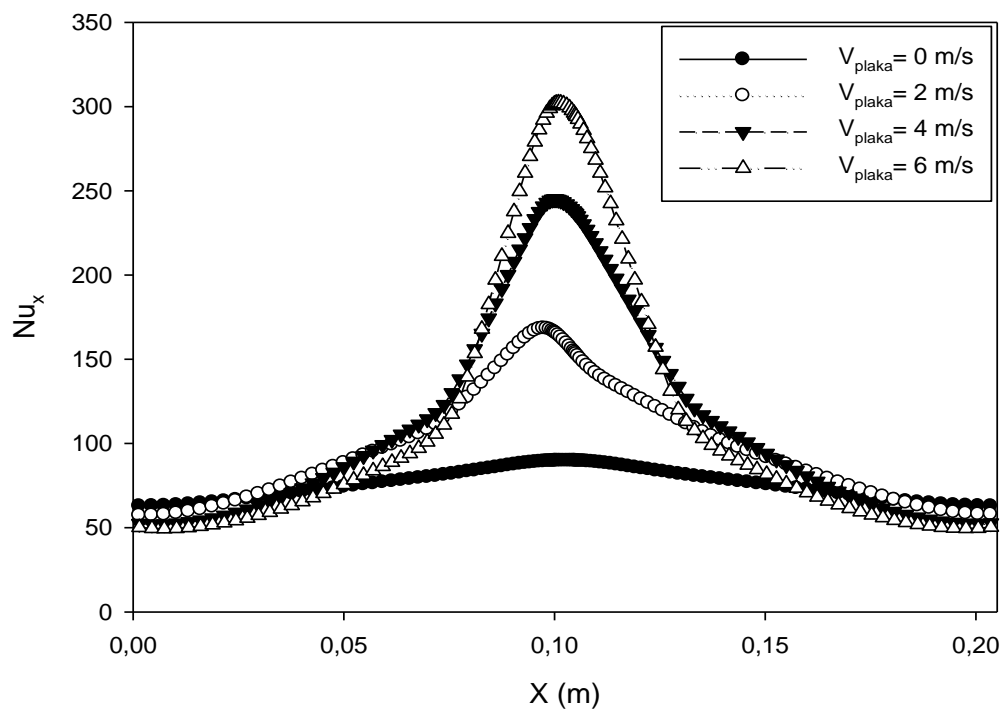

Şekil 7. Farklı plaka hızlarının yerel Nusselt sayısına etkisi.

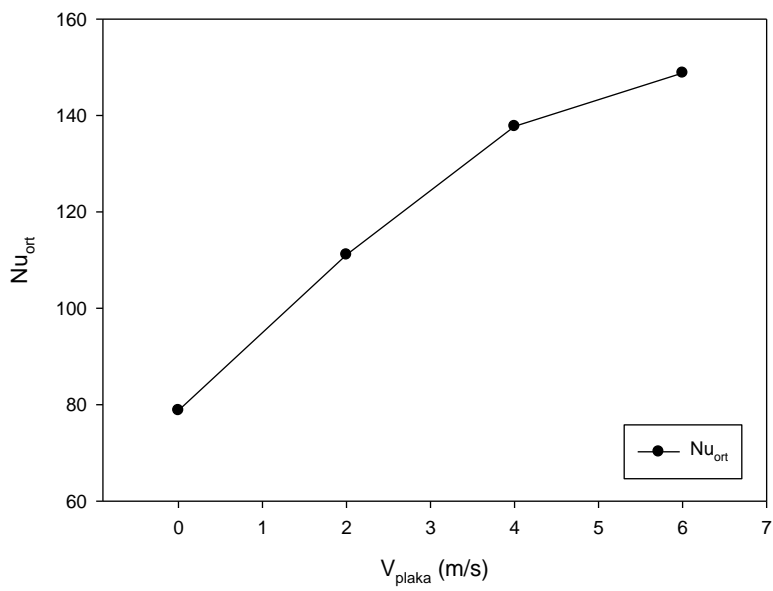

Şekil 8. Farklı plaka hızlarının ortalama Nusselt sayısına etkisi.

Plaka hızı arttıkça özellikle çarpma bölgesinde yerel Nusselt sayısının arttığı, çarpma bölgesinde sağlanan yüksek 1sı transfer etkisinin plaka hareket yönünün aksi yönünde yer değiştirdiği tespit edilmiştir. Plaka hızının artı̧̧na bağlı olarak Ortalama Nusselt sayısının $\left(\mathrm{Nu}_{\text {ort }}\right)$ değerinin de arttığı, ancak bu artışın azalarak devam ettiği tespit edilmiştir. Plaka hareketinin yönünde akan akışkan için, düşük hızlarda oluşan yerel Nusselt sayıları daha düşük, ters yönde oluşan yerel Nusselt sayılarının daha yüksek olduğu tespit edilmiştir. Bunun sebebi; akışın plaka hareketine bağlı olarak hızının aynı yönde olması ve ters yönde olduğu bölgede hidrodinamik sınır tabakanın azalması ve ısı sınır tabakanın artmasından dolayı olduğu söylenebilir.

Plaka hızı arttıkça hidrodinamik sınır tabakanın arttığı dolayısıyla 1sıl sınır tabakanın azaldığı ve 1Sı taşınım katsayısının arttığı görülmüş̧ür. Plaka hızı, $\mathrm{V}_{\text {plaka }}=0-2 \mathrm{~m} / \mathrm{s}$ aralı̆ğında artırıldı̆̆ında Ortalama Nusselt sayısındaki artış $\left(\mathrm{Nu}_{\text {ort }}\right) \% 40,9, \mathrm{~V}_{\text {plaka }}=2-4 \mathrm{~m} / \mathrm{s}$ aralığında arttırıldığında Ortalama Nusselt sayısındaki artış $\left(\mathrm{Nu}_{\text {ort }}\right) \% 23,9, \mathrm{~V}_{\text {plaka }}=4-6 \mathrm{~m} / \mathrm{s}$ aralığında arttırıldığında Ortalama Nusselt sayısındaki artış $\left(\mathrm{Nu}_{\text {ort }}\right) \% 8,1$ olarak belirlenmiştir. Şekil 9'da farklı plaka hızları için çarpma plakası üzerinde oluşan sıcaklık konturları görülmektedir. 


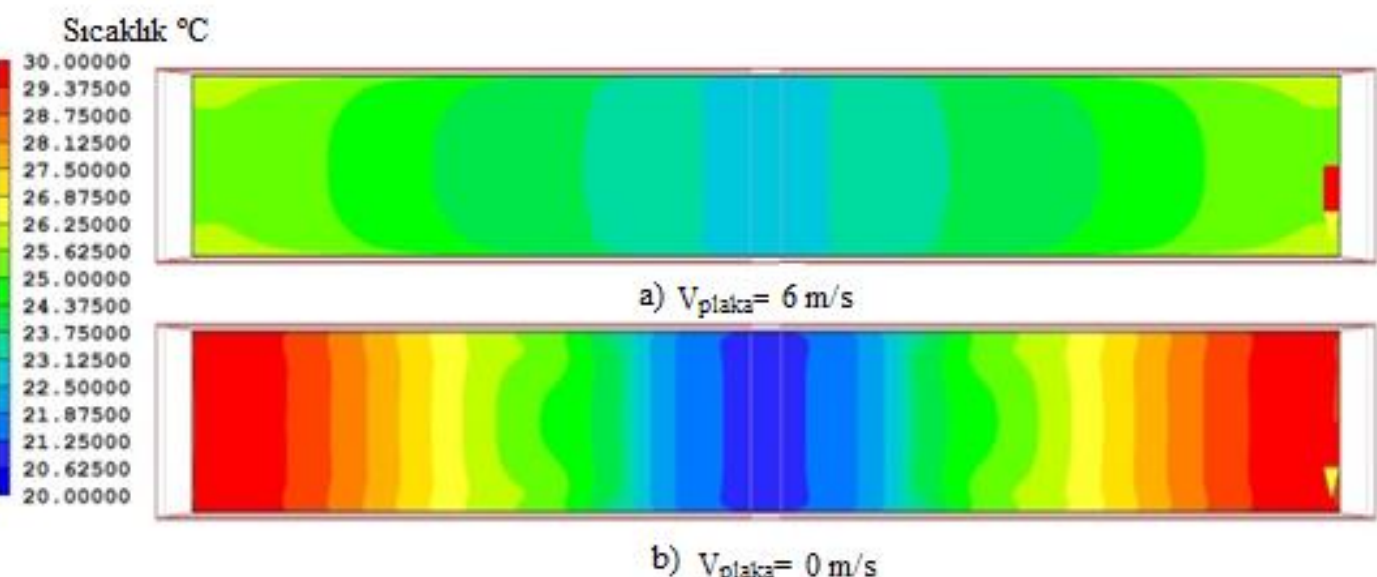

Şekil 9. Plaka Sicaklık konturları a) $V_{\text {plaka }}=6 \mathrm{~m} / \mathrm{s}$ b) $V_{\text {plaka }}=0 \mathrm{~m} / \mathrm{s}$.

\subsection{Farklı Tip Nanoakışkanların Isı Transferine Etkisi $\left(\mathrm{V}_{\text {plaka }}=2 \mathrm{~m} / \mathrm{s}\right)$}

$\mathrm{Bu}$ parametrede farklı tip nanoakışkanlar kullanılarak $\left(\mathrm{Cu}-\mathrm{H}_{2} \mathrm{O}, \mathrm{Al}_{2} \mathrm{O}_{3}-\mathrm{H}_{2} \mathrm{O}, \mathrm{TiO}_{2}-\mathrm{su}\right.$ ve saf su) bir çarpan jetin 1sı transferine olan etkisi incelenmiştir. Nanoakışkanlar $\phi=2,0$ hacimsel orandadır. Jet giriş sıcaklığ $1 T_{\text {girişs }}=20^{\circ} \mathrm{C}, R e=16000$ ve plaka hızı $\mathrm{V}_{\text {plaka }}=2 \mathrm{~m} / \mathrm{s}^{\prime} \mathrm{d} ı r$. Tablo 2'de $20^{\circ} \mathrm{C}^{\prime}$ deki nanoakışkanların termofiziksel özellikleri verilmiştir.

Tablo 2. $20^{\circ} \mathrm{C}$ 'deki nanoakışkanların termofiziksel özellikleri.

\begin{tabular}{ccccccc}
\hline Nanoakışkan & $\begin{array}{c}\text { Yoğunluk, } \\
\boldsymbol{\rho}\left(\mathbf{k g} / \mathbf{m}^{\mathbf{3}}\right)\end{array}$ & $\begin{array}{c}\text { Özgül ısı, } \\
\mathbf{C p},(\mathbf{J} / \mathbf{k g K})\end{array}$ & $\begin{array}{c}\text { Dinamik } \\
\text { Viskozite, } \\
\boldsymbol{\mu ( P a . s )}\end{array}$ & $\begin{array}{c}\text { Kinematik } \\
\text { Viskozite, }\left(\mathbf{m}^{2} / \mathbf{s}\right)\end{array}$ & $\begin{array}{c}\text { Isı İletim } \\
\text { Katsayısı, } \\
\lambda(\mathbf{W} / \mathbf{m K})\end{array}$ & $\begin{array}{c}\text { Isıl Genleşme } \\
\text { Katsayısı, } \boldsymbol{\beta}\left(\mathbf{m} \mathbf{m}^{2} \mathbf{s}\right)\end{array}$ \\
\hline $\mathrm{Cu}-\mathrm{H}_{2} \mathrm{O}$ & 1316.672 & 3148.451 & 0.001099 & 0.000000835 & 0.6684 & 0.000161 \\
$\mathrm{Al}_{2} \mathrm{O}_{3}-\mathrm{H}_{2} \mathrm{O}$ & 1055.836 & 3931.451 & 0.001044 & 0.000000989 & 0.6391 & 0.000154 \\
$\mathrm{TiO}_{2}-\mathrm{H}_{2} \mathrm{O}$ & 1063.236 & 3902.513 & 0.001044 & 0.000000982 & 0.6378 & 0.000153 \\
$\mathrm{Saf} \mathrm{su}$ & 998.2 & 4182.0 & 0.000993 & 0.00000099 & 0.597 & 0.000143 \\
\hline
\end{tabular}

Şekil 10'da farklı tip nanoakışkanlar için yerel Nusselt sayıları, Şekil 11'de farklı tip nanoakışkanların ortalama Nusselt sayısının değişimi verilmiştir.

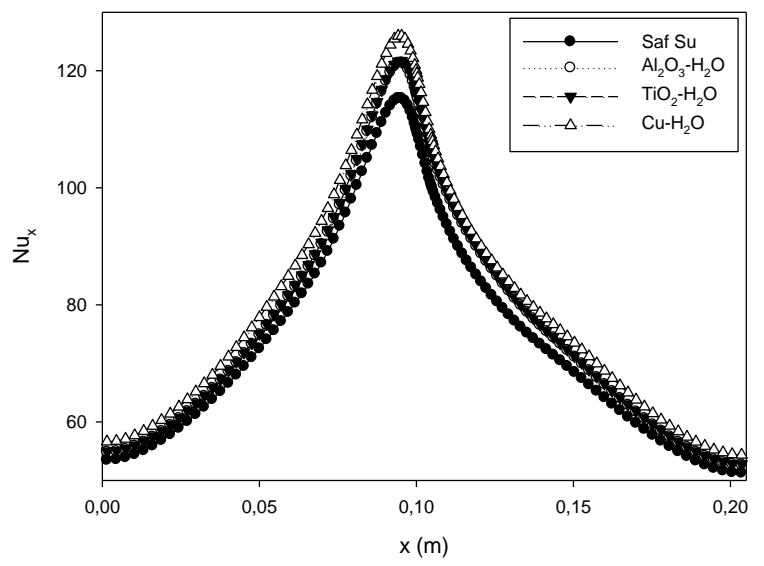

Şekil 10. Farklı nanoakışkanların yerel Nusselt sayısına etkisi. 


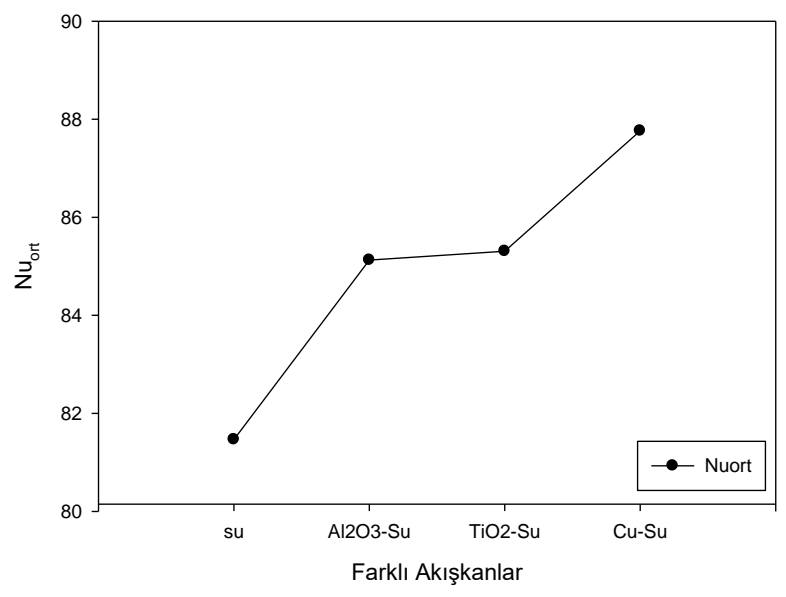

Şekil 11. Farklı nanoakışkanların ortalama Nusselt sayısına etkisi.

Nanoakışkanların aynı hacimsel oranda ve Reynolds sayısında benzer akış özellikleri gösterdiği tespit edilmiştir. En iyi 1sı transferi performansını $\mathrm{Cu}-\mathrm{H}_{2} \mathrm{O}$ nanoakışkanının gösterdiği belirlenmiştir. $\mathrm{Cu}-\mathrm{H}_{2} \mathrm{O}$ nanoakışkanı kullanılması durumunda; ortalama Nusselt sayısında $\mathrm{TiO}_{2}-\mathrm{H}_{2} \mathrm{O}$ 'ye göre $\% 2,9, \mathrm{Al}_{2} \mathrm{O}_{3}-\mathrm{H}_{2} \mathrm{O}$ nanoakışkanına göre \%3,1 ve saf suya göre $\% 7,7$ artış olduğu tespit edilmiştir. Isı transferindeki en fazla artış, en yüksek ısı iletim katsayısı olan nanoakışkanda görülmüştür. Bu sebeple, nanoakışkan isı iletim katsayısının önemli bir parametre olduğu belirlenmiştir. Ayrıca konvansiyonel 1sı transferi akışkanlarına göre (su), nanoakışkan kullanımının 1sı transferinde belirgin bir artış sağlayabildiği tespit edilmiştir. Şekil 12'de farklı nanoakışkanlar için çarpma plakası üzerinde oluşan sıcaklık konturları gösterilmiştir. Sonuç olarak, farklı nanoakışkan kullanılması durumunda, en iyi 1sı transferi performansını $\mathrm{Cu}-\mathrm{H}_{2} \mathrm{O}$ nanoakışkanının gösterdiği belirlenmiştir.

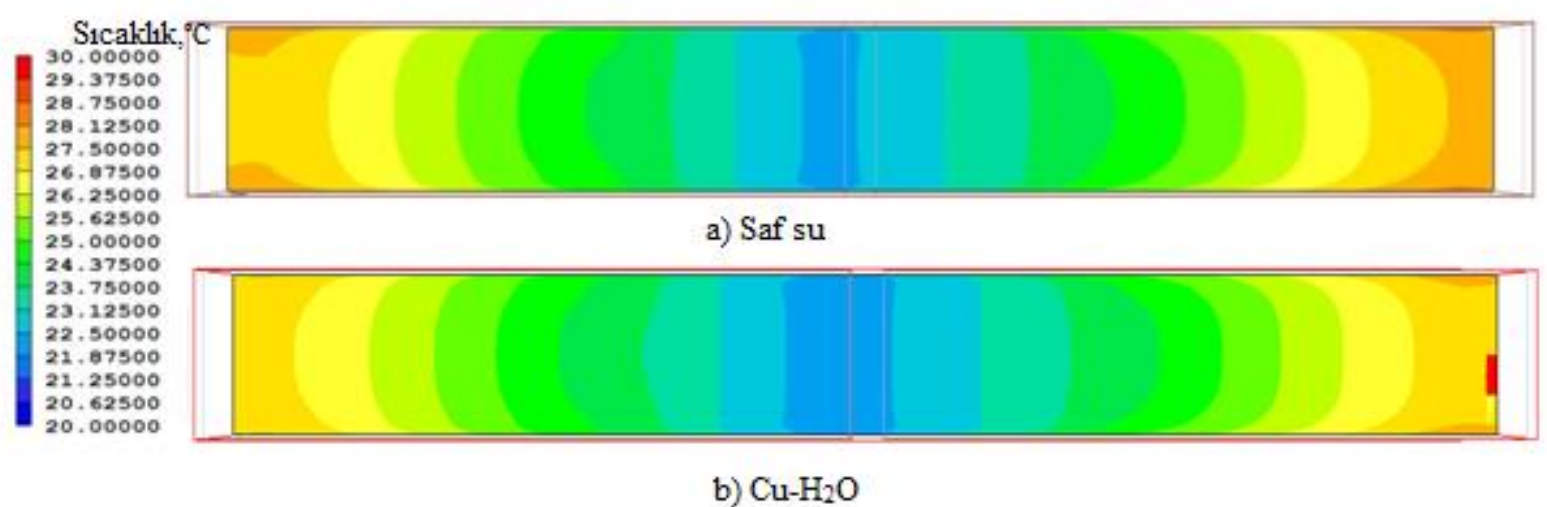

Şekil 12. Plaka Sicaklık konturları a) Saf su, b) $\mathrm{Cu}-\mathrm{H}_{2} \mathrm{O}$.

\section{Sonuç}

Bu çalışmada; tek bir hava jeti kullanılarak, yüksek 1sı akılı hareketli bir plakadan olan 1sı transferinin iyileştirilmesi farklı parametreler için (farklı parçacık çapları, farklı plaka hızları ve farklı tip nanoakışkanlar) sayısal olarak incelenmiştir. Sonuç olarak;

a. $\mathrm{Al}_{2} \mathrm{O}_{3}-\mathrm{H}_{2} \mathrm{O}$ nanoakışkanı kullanılması durumunda $\left(\mathrm{V}_{\text {plaka }}=2 \mathrm{~m} / \mathrm{s}\right)$, nanoparçacık çapı azaldıkça ortalama Nusselt sayısının arttığı ve yüzey sıcaklığının düştüğü, parçacık çapı $\mathrm{D}_{\mathrm{p}}=40 \mathrm{~nm}$ 'den $\mathrm{D}_{\mathrm{p}}=10 \mathrm{~nm}$ 'ye azaltıldığında ortalama Nusselt sayısında $\% 9,1^{\prime}$ lik bir artış olduğu tespit edilmiştir.

b. $\mathrm{Al}_{2} \mathrm{O}_{3}-\mathrm{H}_{2} \mathrm{O}$ nanoakışkanı kullanılması durumunda $\left(\mathrm{V}_{\text {plaka }}=0,2,4,6 \mathrm{~m} / \mathrm{s}\right)$, plaka hızı arttıkça ortalama Nusselt sayısının arttığı, plaka hızı $\mathrm{V}_{\text {plaka }}=0 \mathrm{~m} / \mathrm{s}$ 'den $\mathrm{V}_{\text {plaka }}=6 \mathrm{~m} / \mathrm{s}$ aralığında arttırıldığında ortalama Nusselt sayısının \%88,9 oranında arttırılabileceği tespit edilmiştir.

c. Farklı nanoakışkanların kullanılması durumunda $\left(\mathrm{Cu}-\mathrm{H}_{2} \mathrm{O}, \mathrm{Al}_{2} \mathrm{O}_{3}-\mathrm{H}_{2} \mathrm{O}, \mathrm{TiO}_{2}\right.$-su ve saf su) $\left(\mathrm{V}_{\text {plaka }}=2 \mathrm{~m} / \mathrm{s}\right)$ ise, en iyi isı transfer performansının $\mathrm{Cu}-\mathrm{H}_{2} \mathrm{O}$ nanoakışkanın gösterdiği tespit edilmiştir. $\mathrm{Cu}-\mathrm{H}_{2} \mathrm{O}$ nanoakışkanın saf suya göre \% 7,7 oranında daha iyi ısı transferi sağladığı tespit edilmiştir. 
d. Bu alanda yapılacak gelecekteki çalışmalarda; farklı nanoakışkanların (hibrit nanoakışkanlar vb.) farklı geometrilerde, farklı parametreler için ele alınarak, ısı transferine ve akış özelliklerine etkisinin incelenebileceği değerlendirilmiştir.

\section{Referanslar}

Barewar, S. D., Tawri, S., \& Chougule, S. S. (2019). Heat transfer characteristics of free nanofluid impinging jet on flat surface with different jet to plate distance: An experimental investigation. Chemical Engineering and Processing Intensification, vol.136, pp.1-10. doi:10.1016/j.cep.2018.12.001

Başaran, A., \& Selimefendigil, F. (2013). Numerical study of heat transfer due to twinjets impingement onto an isothermal moving plate. Mathematical and Computational Applications, 18(3), 340-350. doi: 10.3390/mca18030340

Batchelor G. K. (1977). Effect of Brownian-Motion on bulk stress in a suspension of spherical-particles", Journal of Fluid Mechanics, vol.83(1), pp.97-117. doi:10.1017/s0022112077001062

Buonomo, B., Manca, O., Bondareva, N. S., \& Sheremet, M. A. (2019). Thermal and fluid dynamic behaviors of confined slot jets impinging on an isothermal moving surface with nanofluids. Energies, vol.12(11), 2074. doi:10.3390/en12112074

Choi, S. U., \& Eastman, J. A. (1995). Enhancing thermal conductivity of fluids with nanoparticles (No. ANL/MSD/CP-84938; CONF951135-29). Argonne National Lab., IL (United States).

Corcione M. (2011). Empirical correlating equations for predicting the effective thermal conductivity and dynamic viscosity of nanofluids. Energy Conversion and Management, vol. 52(1), pp. 789-793. doi:10.1016/j.enconman.2010.06.072

Devdatta, P.K., Debendra, K.D., \& Ravikanth S.V. (2009). Application of nanofluids in heating building and reducing pollution , Applied Energy, vol.86, pp.2566-2573.

Ersayın, E., \& Selimefendigil, F. (2013). Numerical investigation of impinging jets with nanofluids on a moving plate. Mathematical and Computational Applications, vol.18(3), pp.428-437.

Ho, S.A., Hyungdae, K., Hanglin, J., Soon Ho, K., Wonpyo, \& C., Moo H.K. (2010). Experimental Study Of Critical Heat Flux Ebhancement During Forced Convective Flow Boiling Of Nanofluid On A Short Heated Surface, Int.J. Multiphase Flow, vol.36, pp.375-384.

Kakaç, S., \& Pramuanjaroenkıj, A. (2009). Review of convective heat transfer enhancement with nanofluids. International Journal of Heat and Mass Transfer, vol.52, pp.3187-3196. doi:10.1016/j.ijheatmasstransfer.2009.02.006

Kasaeian, A., Eshghi, A.T., \& Sameti, M. (2015). A Review on The Applications of Nanofluids in Solar Energy Systems , Renew. Sust. Energ. Rev., vol.43, pp.584-598. doi:10.1016/j.rser.2014.11.020

Khan, I. A. (2021). Experimental validation of enhancement in thermal conductivity of titania/water nanofluid by the addition of silver nanoparticles. International Communications in Heat and Mass Transfer, vol.120, 104910. doi: 10.1016/j.icheatmasstransfer.2020.104910

Kilic M., \& Başkaya Ş. (2017). Farklı geometride akış yönlendiriciler ve çarpan jet kullanarak yüksek 1sı akılı bir yüzeyden olan 1S1 transferinin iyileştirilmesi, Journal of the Faculty of Engineering and Architecture of Gazi University, vol.32(3), pp.693-707. doi: 10.17341/gazimmfd.337616

Kilic, M. (2013). Çarpmalı Akışkan Jetlerle Kanal içine Yerleştirilmiş Elemanlardan Olan Konveksiyonla Isı Transferinin Sayısal ve Deneysel Olarak incelenmesi (Doktora Tezi, Gazi Üniversitesi, Fen Bilimleri Enstitüsü, Ankara).

Kilic, M., \& Ali, H. M. (2019). Numerical investigation of combined effect of nanofluids and multiple jets on heat transfer. Thermal Science, 23(5 Part B), 3165-3173. doi:10.2298/TSCI171204094K

Kilic, M., \& Ozcan, O. (2017). Numerical investigation of heat transfer and fluid flow of nanofluids with jets: International Conference On Advances and Innovations in Engineering (ICAIE); pp.434-440.

Lahari, M. C., Sai, P. S. T., Swamy, K. N., KrishnaMurthy, N., \& Sharma, K. V. (2018). Investigation on heat transfer properties of water based $\mathrm{TiO} 2-\mathrm{ZnO}$ nanofluids. In IOP conference series: materials science and engineering vol.45(1),pp.012092. doi:10.1088/1757-899X/455/1/012092 
Li., Xuan Y., \& Yu F. (2012). "Experimental investigation of submerged single jet impingement using Cu-Water Nanofluid. Applied Thermal Engineering, vol.36 (1), pp.426-433. doi:10.1016/j.applthermaleng.2011.10.059

Pak, B C., \& Cho, Y. I.(1998). Hydrodynamic and heat transfer study of dispersed fluids with submicron metallic oxide particles, Experimental Heat Transfer an International Journal, vol.11(2), pp.151-170. doi: 10.1080/08916159808946559

Peyghambarzadeh, S. M., Hashemabadi, S. H., Hoseini, S. M., \& Jamnani, M. S. (2011). Experimental study of heat transfer enhancement using water/ethylene glycol based nanofluids as a new coolant for car radiators. International communications in heat and mass transfer, vol.38(9), pp.1283-1290. doi:10.1016/j.icheatmasstransfer.2011.07.001

Sarkar, J., Ghosh, P., \& Adil, A. (2015). A review on hybrid nanofluids: recent research, development and applications. Renewable and Sustainable Energy Reviews, vol.43, pp.164-177. doi:10.1016/j.rser.2014.11.023

Selvakumar, P., \& Suresh, S.,(2012). Convective Performance Of CuO/Water Nanofluid In An Electronic Heat Sink, Exp., Thermal Fluid Science,vol.40, pp.57-63. doi: 10.1016/j.expthermflusci.2012.01.033

Sharif, M. A. R., \& Banerjee, A. (2009). Numerical analysis of heat transfer due to confined slot-jet impingement on a moving plate. Applied Thermal Engineering, vol.29(2-3), pp.532-540. doi: 10.1016/j.applthermaleng.2008.03.011

Sun, B., Zhang, Y., Yang, D., \& Li, H. (2019). Experimental study on heat transfer characteristics of hybrid nanofluid jets. Applied Thermal Engineering, vol.151, pp.556-566. doi:10.1016/j.applthermaleng.2020.114920

Suresh, S., Chandrasekar, S., \& Sekhar, C. (2011). Experimental Studies on Heat Transfer and Friction Factor Characteristics of $\mathrm{CuO} /$ Water Nanofluid under Turbulent Flow in a Helically Dimpled Tube, Exp.Thermal Fluid Sci., vol.35, pp.542-549. doi: 10.1016/j.expthermflusci.2010.12.008

Wang B.X., Zhou L.P., \& Peng X.F. (2006). Surface and size effects on the specific heat capacity of nanoparticles, International Journal of Thermophysics, vol.27(1), pp.139-151.

Xuan, Y., \& Li, Q. (2000). Heat transfer enhancement of nanofluids. International Journal of Heat and fluid flow, vol.21(1), pp.58-64. doi: 10.1016/S0142-727X(99)00067-3 